\title{
1 The interplay between maritime security and the 1982 United Nations Convention on the Law of the Sea: help or hindrance?
}

\author{
Sofia Galani and Malcolm D. Evans
}

\section{INTRODUCTION}

The seas and oceans cover 70 per cent of the earth's surface, and 90 per cent of world trade is by sea. ${ }^{1}$ The oceans have always been a source of power and wealth for states who have been keen to delimit their own maritime limits, but states have also sought to ensure that the high seas remain open to all users. Major maritime nations have enjoyed a military advantage over smaller coastal and landlocked states by using and controlling the maritime domain for the purposes of navigation, commerce and naval warfare. Economic benefits from the development of the blue economy agenda have also become added to the exploitation of fisheries and of marine natural resources, which have traditionally contributed to the economies of states. ${ }^{2}$

Nevertheless, the continuing economic development of the oceans has been overshadowed by increasing maritime security threats. While traditional forms of inter-state disputes regarding the use and delimitation of their maritime zones remain, new maritime security threats posed by non-state actors have

\footnotetext{
1 European Union Maritime Security Strategy, Responding Together to Global Challenges, A guide for stakeholders, available at https:/ec.europa.eu/maritimeaffairs/ sites/maritimeaffairs/files/leaflet-european-union-maritime-security-strategy_en.pdf.

2 The African Charter on Maritime Security, Safety and Development in Africa (the Lomé Charter) (15 October 2016) defined blue/ocean economy as the sustainable economic development of oceans using techniques such as regional development to integrate the use of seas and oceans, coasts, lakes, rivers and underground water for economic purposes, including, but without being limited to, fisheries, mining, energy, aquaculture, and maritime transport, while protecting the sea to improve social well-being, available at au.int/en/treaties/african-charter-maritime-security-and-safety -and-development-africa-lome-charter 4.
} 
encouraged states to reconsider their understanding of maritime security and rethink the use and protection of their maritime domain. The 9/11 attacks were a wake-up call for the US, which realized that maritime infrastructure, including ports and maritime installations, might be vulnerable to terrorist attacks as well as that the oceans can themselves be used for the planning of terrorist activities, such as through the transfer of weapons or terrorists. ${ }^{3}$ The bombings of USS Cole and MV Limburg, the resurgence of piracy, the refugee crisis in the Mediterranean Sea, and the proliferation of weapons of mass destruction (WMDs) aggravated the concerns about the threats posed to maritime security by non-state actors. ${ }^{4}$ All this has brought maritime security to the forefront of thinking concerning the international law of the sea, with states and international organizations publishing, for the first time, their maritime security strategies. ${ }^{5}$

Unsurprisingly, states, scholars and practitioners turn to the 1982 United Nations Convention on the Law of the Sea (LOSC) - the 'Constitution of the Oceans' - to seek help on how to protect their maritime domain against new maritime security threats. ${ }^{6}$ LOSC was drafted for the purposes of ensuring the peaceful use of oceans but is considered a living instrument. ${ }^{7}$ This means that LOSC can be interpreted in a way that allows for current security challenges and threats to fit within the meaning of its various provisions. ${ }^{8}$ It is inevitable, however, that certain emerging activities and concepts closely interlinked with

3 The National Strategy for Maritime Security (September 2005) available at https://georgewbush-whitehouse.archives.gov/homeland/maritime-security.html.

${ }_{4}$ Report of the Secretary-General, Oceans and the law of the sea (10 March 2008) (A/63/63) [54]-[113].

5 In addition to the US National Strategy for Maritime Security (n 3), see the UK National Strategy for Maritime Security (May 2014) available at https://assets .publishing.service.gov.uk/government/uploads/system/uploads/attachment_data/file/ 310987/20140508 NSMS.pdf and the French National Strategy for the Security of Maritime Areas (22 October 2015) available at https://www.gouvernement.fr/sites/ default/files/contenu/piece-jointe/2016/01/strategie_nationale_de_surete_des_espaces _maritimes_en_national_strategy_for_the_security_of_maritime_areas.pdf. $\overline{\text { For }}$ the maritime security strategies and plans of international and regional organizations, see Section 2.2.

6 United Nations Convention on the Law of the Sea 1982, 1833 UNTS 397. 'A Constitution for the Oceans' - Remarks by Tommy T.B. Koh, of Singapore. President of the Third United Nations Conference on the Law of the Sea, available at https://treaties.un.org/Pages/ViewDetailsIII.aspx?src=TREATY\&mtdsg_no=XXI-6\& chapter $=21 \&$ Temp $=$ mtdsg $3 \&$ clang $=$ fr . 2016).

8 For an in-depth study of maritime security and the international law of the sea, see N Klein, Maritime Security and the Law of the Sea (Oxford University Press (OUP) 2010). 
maritime security, such as the use of unmanned systems or the blue economy agenda, will not easily fit within the provisions and purposes of LOSC. This gives rise to the question whether insisting on relying on LOSC for answers to maritime security problems helps or hinders efforts to secure the oceans.

This volume is therefore aimed at revisiting LOSC from a maritime security perspective. The underlying question that all contributors are invited to address is: does the 1982 LOSC help or hinder maritime security? This chapter will set the scene for the examination of this question by discussing the definition of maritime security, evaluating the approach of LOSC to maritime security and making an initial assessment of the interplay between LOSC and the responses of states to maritime security. It will argue that maritime security is not simply a concept that needs defining but a blend of threats and activities by state and non-state actors. This will lend support to the argument that the emerging blend of threats and activities at sea represents a paradigm shift in the international law of the sea. As a result, LOSC can offer some help in achieving maritime security but it is time to commence thinking about new tools and conventions that will strengthen the security of the oceans.

\section{MARITIME SECURITY: IN SEARCH OF A MEANING?}

\subsection{Maritime Security in the Literature}

The term maritime security has not yet acquired a fixed meaning. Efforts to deconstruct its exact meaning have been made both in the literature and in the policies of states. In this chapter, we will use the definitions found in the literature as a starting point. We will then turn to comparing how states have interpreted maritime security in their maritime security strategies/policies and how LOSC understands maritime security in order to evaluate whether LOSC can help or hinder states in their efforts to achieve maritime security.

The existing literature has focused more on the semantics and the actual meaning of security. It has been argued that security has a negative and a positive dimension. In its negative sense, security reflects a lack of threats, while in its positive sense, it 'projects a certain ideal-typical end state that has to be reached'. ${ }^{9}$ In the maritime context, Klein has defined maritime security to mean 'the protection of a state's land and maritime territory, infrastructure, economy, environment and society from certain harmful acts occurring at sea'. ${ }^{10}$ This definition indicates what could threaten maritime security,

\footnotetext{
9 C Bueger, 'What Is Maritime Security?' (2015) 53 Marine Pol'y 159.

10 Klein (n 8) 8.
} 
including traditional inter-state disputes as well as a range of other threats against maritime infrastructure, economic development, the marine environment and human security. ${ }^{11}$ To reflect these different threats, Bueger refers to a 'maritime security matrix' that consists of four core dimensions: national security, marine environment, economic development and human security. ${ }^{12}$ Each of these dimensions encompasses further threats and activities without it always being easy to determine under which specific dimension a threat or activity falls. For example, piracy threatens economic development as well as the human rights of seafarers and the resilience of coastal communities. ${ }^{13}$ Marine pollution also has a dual effect as it affects the marine environment and weakens the potential for economic development of the polluted areas.

\subsection{Maritime Security in State Practice}

In addition to understanding of the semantics and the identification of threats to maritime security, it is important to understand what states actually do in order to achieve maritime security. ${ }^{14}$ The activity and practice of states in response to maritime security constitutes an essential element of the conceptualization of maritime security and a prerequisite for a discussion of whether these activities can be accommodated or hindered by LOSC.

The term 'maritime security' entered the oceans governance debate in October 2005 when the US made a breakthrough by publishing the first national strategy for maritime security..$^{15}$ The US strategy does not define maritime security. Its drafters, however, explained that maritime security should be understood to be 'required to ensure freedom of the seas; facilitate freedom of navigation and commerce; advance prosperity and freedom; and protect the resources of the ocean'. ${ }^{16}$ The US strategy identifies terrorism as a major threat to maritime security because it has increased 'the nature of the nonmilitary, transnational, and asymmetric threats in the maritime domain'.${ }^{17}$ According to the US strategy, maritime terrorism can be manifested in attacks against vessels, ports and maritime installations, the use of shipping for the planning

\section{Ibid, 9 .}

Bueger (n 9) 160-161.

13 S Galani, 'Somali Piracy and the Human Rights of Seafarers' (2016) 1 NQHR 71; Jason P Abbott and Neil Renwick, 'Pirates? Maritime Piracy and Societal Security in Southeast Asia' (1999) 11 Pacifica Review: Peace, Security \& Global Change 4.

14 Bueger (n 9) 162-163.

15 US National Strategy for Maritime Security (n 3).

16 Ibid, 2.

17 Ibid, 3. 
or funding of terrorism activities, and the transfer of WMDs. ${ }^{18}$ Although the threat of maritime terrorism has not fully materialized yet, the US national strategy was heavily influenced by the $9 / 11$ attacks, which succeeded in sabotaging the safety of air carriers, and the bombing of USS Cole, an American guided missile destroyer, while in the port of Aden in Yemen. ${ }^{19}$ Other threats identified in the strategy concern inter-state conflicts, piracy, illegal seaborne immigration and environmental degradation. ${ }^{20}$ In response to these threats, the US strategy urged states to enhance inter-state cooperation, increase maritime domain awareness (MDA), embed security into commercial practices, develop public and private security mechanisms and assure the continuity of the maritime transportation system. ${ }^{21}$ The US approach to maritime security shows that while some of the threats identified are included in LOSC, such as piracy and environmental degradation, the US has completely shifted its efforts towards new tools and mechanisms not found in LOSC such as MDA policies, urging states to think outside the LOSC framework for new ways to secure the oceans.

This reaction of states has been accelerated by the rise in Somali piracy. NATO published its Alliance Maritime Strategy in 2011 when the detrimental effects of uncontrollable pirate activities had started becoming evident. ${ }^{22}$ The challenges posed by the transnational criminal activities of pirates and terrorists as well as of weapons, drugs and human traffickers were also cited in the NATO strategy. In addition, the strategy was critical of merchant vessels using flags of convenience (FoCs), posing jurisdictional barriers to enforcement efforts. ${ }^{23}$ In response to these challenges, NATO emphasized the importance of its law enforcement operations in addition to its surveillance and information-sharing activities. The NATO strategy did not cite LOSC but noted that all their operations and activities must be in accordance with international law. ${ }^{24}$ However, most of their proposed responses towards enhancing maritime security, including crisis management and capacity building, are not addressed in LOSC, underlining the need to consider new responses to the emerging threats and new international tools to regulate these responses.

\footnotetext{
18 Ibid, 4-5.

19 Two years later, the French oil tanker MV Limburg was also attacked while in the Arabian Sea. See J Henley and H Stewart, 'Al-Qaida suspected in tanker explosion' (The Guardian, 2002) available at https://www.theguardian.com/world/2002/oct/07/ alqaida.france.

${ }_{20}$ US National Strategy for Maritime Security (n 3) 4-6.

${ }^{21}$ Ibid, 13-23.

22 NATO Alliance Maritime Strategy (18 March 2011) available at www.nato.int/ cps/ua/natohq/official_texts_75615.htm.

23 Ibid, [6].

24 Ibid, [15].
} 
Three key regional actors, namely the European Union (EU), the African Union (AU) and the Association of Southeast Asian Nations (ASEAN), also acknowledged the importance of investing in maritime security by publishing their own maritime security strategies and plans. In its 2014 Maritime Security Strategy, the EU explained that maritime security 'is understood as a state of affairs of the global maritime domain, in which international law and national law are enforced, freedom of navigation is guaranteed and citizens, infrastructure, transport, the environment and marine resources are protected' ${ }^{25}$ It echoed the concerns of the US regarding inter-state disputes, maritime terrorism, proliferation of WMDs, piracy, illegal migration, environmental and man-made disasters, and identified illegal and unregulated archaeological research and pillage of archaeological objects as an additional threat to maritime security. ${ }^{26}$ The strategy also outlined a number of steps that the EU considers necessary to achieve maritime security. These include the strengthening of the EU External Action via maritime operations, bilateral agreements, international forums, etc.; the collection of maritime surveillance information that can increase maritime awareness; capacity building; risk management; crisis response and maritime security research. ${ }^{27}$ ASEAN is also committed to enhancing maritime security and has been regularly updating its work plans for maritime security driven by sovereignty disputes, cross-border crime, piracy and natural disasters in the region. ${ }^{28}$ Shared awareness, confidence-building measures based on international law, including LOSC, and capacity building are the priority areas identified by ASEAN that can serve as the primary guideposts for cooperative efforts towards achieving maritime security. ${ }^{29}$

The AU has carefully considered the wealth and opportunities the exploitation of the oceans can offer to African countries and has tried to develop a comprehensive approach to maritime security. In its 2050 Africa's Integrated Maritime Strategy (2050 AIM Strategy), the AU listed all the previously mentioned threats to maritime security while adding illegal oil bunkering and crude oil theft as well as the lack of and poorly maintained navigational aids to the

25 Council of the European Union, European Union Maritime Security Strategy (11205/14) (24 June 2014) 2.

Ibid, 8 .

27 Ibid, 8-15.

28 ASEAN Regional Forum Work Plan for Maritime Security 2018-2020 available at aseanregionalforum.asean.org/wp-content/uploads/2019/01/ANNEX-3-.pdf 7. See also, 2015-2017 ASEAN Regional Forum Work Plan for Maritime Security (6 August 2015) available at cil.nus.edu.sg/wp-content/uploads/2019/02/2015-2017-ARF -WP-FOR-MARITIME-SECURITY.pdf.

29 ASEAN Regional Forum Work Plan for Maritime Security 2018-2020, ibid, 3. 
list of vulnerabilities. ${ }^{30}$ The 2050 AIM Strategy put forward a comprehensive framework with a list of conventional and innovative measures needed to achieve maritime security in Africa, such as delineation of maritime boundaries, the establishment of a Combined Exclusive Maritime Zone of Africa (CEMZA), environmental monitoring, the creation of regional maritime operational centres and the development of further integrated strategies on maritime tourism and aquaculture. ${ }^{31}$ The vision of the AU to promote its blue economy agenda and enhance human security by achieving maritime security was further developed in the African Charter on Maritime Security, Safety and Development in Africa (the Lomé Charter). ${ }^{32}$ The Lomé Charter is a momentous document as it is the first legally binding agreement aimed at promoting the blue economy through the enhancement of maritime security. ${ }^{33}$

The first maritime security agreement, however, was pioneered by the Caribbean Community (CARICOM). Article 2 of CARICOM Maritime and Airspace Security Cooperation Agreement sets out the objectives of the agreement, which are to improve cooperation and the capacity of states in conducting law enforcement operations in relation to the prevention of drug trafficking, terrorist offences, smuggling, immigration, pollution, piracy, hijacking and other offences as well as to respond to threats to security as a result of natural and other disasters and to protect offshore installations. ${ }^{34}$ The agreement provides a comprehensive framework for how law enforcement operations should be conducted and how subsequent matters, such the disposition of seized property, should be dealt with. Despite the ambitions of the drafters, only two states have so far ratified the agreement, which means that it is not in force yet. ${ }^{35}$

The reading of the regional maritime security strategies and agreements leads to several conclusions relevant for an understanding of maritime security. First, states still define maritime security by identifying what threatens oceans. While certain threats feature in all the above-mentioned documents, others might be unique or more significant in certain regions, such as pillage of archaeological objects in European waters, oil theft in Africa and natural

30 African Union, 2050 Africa's Integrated Maritime (AIM) Strategy (29 July 2013) 10-11 available at cggrps.org/wp-content/uploads/2050-AIM-Strategy_EN.pdf.

31 Ibid, 15-26.

32 Lomé Charter (n 2).

33 E Egede, 'Africa's Lomé Charter on maritime security: What are the next steps?' (2017) Piracy Studies, available at piracy-studies.org/africas-lome-charter-on-maritime -security-what-are-the-next-steps/.

34 CARICOM Maritime and Airspace Security Cooperation Agreement, 4 July 2008, 1 .

35 Ibid, Article 27. 
disasters in Southeast Asia and the Caribbean. It is therefore difficult to draw a comprehensive list of maritime security threats that could lead to a single definition of maritime security. The diverse maritime security threats also result in the adoption of different measures in response to these threats. The capacity of each regional actor also dictates what is considered needed to enhance maritime security. On the one hand, the EU mostly acts through its European External Action Service and ASEAN through its established forums. On the other hand, the AU tries to develop integrated responses at sea in a continent that still struggles to achieve peace and security on land. ${ }^{36}$ Some of the proposed measures and mechanisms of the regional actors, such as the law enforcement operations and cooperation mechanisms against piracy, are conventional and could fall within the LOSC provisions. However, most of the other initiatives found in the various mechanisms, such as capacity building and surveillance, might challenge the LOSC framework. The approach of the AU and CARICOM also shows that instead of relying on LOSC for solutions, states have started implementing distinct comprehensive mechanisms intended to achieve maritime security.

All this reinforces the argument of this chapter that maritime security can only be understood as a blend of threats and activities by state and non-state actors rather than a concept that can have a single definition, and as a result the LOSC framework might no longer be suitable to address all of them. It is therefore time to turn to how LOSC understands maritime security and evaluate whether LOSC reflects the current concerns of states in relation to maritime security.

\subsection{Maritime Security and LOSC}

A first step to take in order to examine how LOSC understands maritime security is to conduct a textual analysis of the provisions that refer to security. This task is important because LOSC does not use the term 'maritime security' per se, and as a result it does not define it. It does, however, have scattered references to security that are worth a closer look. In the preamble, the drafters expressed their belief that the codification of the international law of the sea 'will contribute to the strengthening of peace, security, cooperation and friendly relations among all nations' and 'will promote the economic and social advancement of all peoples of the world'. This, essentially, reflects the aim of LOSC to allow states to maximize the utilization of marine resources in a peaceful and regulated manner that can minimize inter-state disputes.

36 P Brits and M Nel, 'African Maritime Security and the Lomé Charter: Reality or Dream?’ (2018) 27 African Security Review 2. 
Article 19(1) LOSC also refers to security by defining innocent passage as not being 'prejudicial to the peace, good order or security of the coastal State' and Article 19(2) LOSC provides a list of activities that can be prejudicial to peace, good order or security of a coastal state. Some of the activities mentioned in Article 19(2) LOSC, such as the use of force and military operations, are traditionally understood to threaten the security of a coastal state. In addition, it has been suggested that, by including marine pollution and illegal fishing as activities harmful to the security of a coastal state in Article 19 LOSC, 'the LOSC permits a wider definition of "security" than what might be ordinarily inferred from the word alone' ${ }^{37}$ This is further supported by the sole reference to security in Article 25 LOSC, which gives a coastal state the right 'to suspend temporarily in specified areas of its territorial sea the innocent passage of foreign ships if such suspension is essential for the protection of its security'. Another explicit reference to security can be found in Article 138 LOSC in relation to the conduct of states in the Area which shall be, inter alia, 'in the interests of maintaining peace and security and promoting international cooperation and mutual understanding'. This reference to security reinforces the overarching aim of the convention mentioned above. LOSC further refers to the security of states in Article 302 permitting them not to disclose information that is against the interests of their security during the procedures for settlement of disputes set forth by the convention. Klein argues that 'such an exclusion holds particular importance when it is recalled that the LOSC entails a compulsory dispute settlement system' ${ }^{38}$ To better understand the importance attached to the security of states under this provision, one should also consider Article 298(1)(b), which permits states to reject the compulsory jurisdiction of the LOSC procedures with regard to military activities. ${ }^{39}$ Whereas Article 298(1) does not explicitly refer to security, military activities are traditionally understood to be closely interlinked with the notion of a state's security.

Several provisions of LOSC also refer to safety. Linguistically, the terms 'security' and 'safety' are different in English, but the same word is used for both terms in French (securité) and Spanish (seguridad)..$^{40}$ It therefore

37 S Kaye, 'Freedom of Navigation in a Post 9/11 World: Security and Creeping Jurisdiction' in D Freestone, R Barnes and D Ong (eds), The Law of the Sea Progress and Prospects (OUP 2006) 349.

${ }_{38}$ N Klein, 'Maritime Security' in D Rothwell, A Oude Elferink, K Scott and T Stephens (eds), The Oxford Handbook of the Law of the Sea (OUP 2015) 597.

39 For the criteria that define a military operation see Case concerning the detention of three Ukrainian naval vessels (Ukraine v. Russian Federation), Provisional Measures ITLOS, 25 May 2019. See also the discussion in Section 3.1.

40 The IMO has now distinguished between security and safety in French and Spanish, and several of its initiatives, including Chapter XI of the Safety of Life at Sea Convention (SOLAS Convention) and the ISPS Code, use distinct terms in 
becomes relevant to examine how the LOSC provisions understand safety, given that safety issues fall within the broader maritime security debate as suggested by the relevant literature and policies. LOSC deals with safety to a greater extent and in a more explicit manner than it does with security. Safety in LOSC encompasses the safety of navigation, the safety of human life, and the protection of the marine environment. For example, LOSC stipulates the rights and duties of states with regard to the safety of navigation, which is a prerequisite for both the safety of life at sea and the protection of the marine environment. ${ }^{41}$ The use of navigation and safety aids as well as safety zones is important for the regulation of maritime traffic, the prevention of collision of vessels or other accidents at sea that cause unintentional discharge of other pollution from vessels and the protection of persons at sea. Article 242 LOSC seeks to promote international cooperation in marine scientific research and the exchange of relevant information in order to prevent and control damage to the health and safety of persons and to the marine environment. The safety of human life is also discussed in Article 94 LOSC regarding the duties of flag states to ensure safety at sea and Article 98 LOSC concerning the duty of states to render assistance to any person found at sea in danger or in distress. Both provisions have a strong focus on the interests of humans at sea and have attracted the attention of human rights advocates who seek to rely on LOSC to safeguard the right to life at sea. ${ }^{42}$ Admittedly, LOSC was not meant to address issues relating to the protection of human rights at sea but the increasing human rights violations that occur in the maritime domain justify the interpretation that the duty of states to ensure safety at sea or render assistance to those in need is translated into their duty to protect the right to life at sea. These references to the human element in LOSC have been gradually integrated into the broader understanding of maritime security, with human security at sea reflecting one of its core dimensions. ${ }^{43}$

What can be deduced from the evaluation of the LOSC references to security and safety is that although LOSC does not expressly deal with maritime

French ('sûreté maritime' as opposed to 'securité maritime') and Spanish ('protección marítima' as opposed to 'seguridad marítima') to refer to security and safety issues. See Klein (n 8) 8. See also the French version of LOSC available at www.un.org/depts/los/ convention_agreements/texts/LOSC/LOSC_f.pdf.

${ }_{41}$ LOSC, Articles 21, 22, 39, 42, 43, 60, 147, 194, 225. Articles 212 and 222 refer to the safety of air navigation.

42 I Papanicolopulu, International Law and the Protection of People at Sea (OUP 2018) 174-176.

43 Bueger (n 9) 161; Kriangsak Kittichaisaree, 'A Code of Conduct for Human and Regional Security around the South China Sea' (2010) 32 ODIL 133; S Galani, 'Maritime Security and Human Rights: The Role of the EU and its Member States in the Protection of Human Rights in the Maritime Domain' IJMCL, forthcoming. 
security, it does address maritime security in the context of other matters. LOSC also has express provisions concerning the duty of states to prevent slave trade (Article 99), repress piracy (Articles 100-107) and suppress drug trafficking (Article 108). Overall, LOSC contains provisions aimed at addressing traditional security threats arising from sovereignty inter-state disputes and military activities and non-traditional security threats, such as piracy, illegal fishing, marine pollution, marine safety, human security, and trafficking in drugs and humans. This shows that what LOSC perceives as a threat to the maritime domain does not differ much from the threats identified by states, although some threats, such as maritime terrorism or the proliferation of WMDs, fall outside the language of LOSC. What demands more attention, however, is whether the LOSC framework is adequate to address the increasing number of these security threats or to accommodate what states do in the name of maritime security. This takes us back to the central question of this collection: whether LOSC helps or hinders maritime security, and whether it is time to look beyond LOSC in order to secure our oceans. This is assessed in the next section.

\section{THE INTERPLAY BETWEEN MARITIME SECURITY AND LOSC}

Given the rise in maritime security threats and the proliferation of maritime security initiatives by states and non-state actors, evaluating how each of them could fit within LOSC might prove an enormous task. This section will therefore evaluate how some of the most critical responses of states to maritime security have challenged key LOSC principles, urging us to reconsider the role of LOSC in achieving maritime security.

\subsection{Law Enforcement Operations}

Law enforcement is essential to enable states to maintain maritime security. The importance of law enforcement operations is reflected in all maritime strategies, which prioritize them as effective means to prevent and suppress illegal activities at sea. They include 'surveillance, stopping and boarding vessels, search or inspection, reporting, arrest or seizure of persons and vessels, detention, and formal application of law by judicial or other process, including imposition of sanctions' ${ }^{44}$ Guilfoyle has noted that 'in an age of maritime security, actionable law enforcement [intelligence] is no longer an

44 WT Burke, The New International Law of Fisheries: LOSC 1982 and Beyond (Clarendon Press 1994) 303. 
issue for coastguards alone; it is increasingly an issue for navies as well' ${ }^{45}$ This has made the distinction between law enforcement operations and military operations rather difficult, with the International Tribunal for the Law of the Sea (ITLOS) noting that 'the traditional distinction between naval vessels and law enforcement vessels in terms of their roles has become considerably blurred' ${ }^{46}$ According to the view of ITLOS, their distinction 'must be based primarily on an objective evaluation of the nature of the activities in question, taking into account the relevant circumstances in each case' ${ }^{47}$ The way ITLOS applied these criteria to the dispute between Ukraine and Russia concerning the detention of three Ukrainian naval vessels and 24 Ukrainian service members, however, has supported the conclusion that few operations can be classified as military in nature. ${ }^{48}$ This can have a tremendous impact on the judicial scrutiny that law enforcement operations can be subject to as only military operations can be exempted from compulsory inter-state proceedings under Article 298 LOSC.

This means that states seeking to protect maritime security through law enforcement operations have to strictly comply with the rights and duties they have in the different maritime zones as determined by LOSC. Coastal states, for example, enjoy extensive sovereign rights over their territorial waters, which are comparable to the sovereign rights they enjoy on land. To enforce these rights and effectively address maritime security threats, they can take action against vessels 'engaged in terrorism, transnational crimes (such as drug trafficking and people smuggling), intentional pollution, illegal fishing, and intelligence gathering' ${ }^{49}$ The enforcement powers of coastal states decrease in the contiguous zone and the exclusive economic zone (EEZ). In the contiguous zone, Article 33 LOSC gives coastal states the power to exercise control for the prevention and punishment of infringement of its customs, fiscal, immigration or sanitary laws and regulations, while in the EEZ they can board, inspect, arrest and institute proceedings against vessels engaged in illegal fishing or in breach of pollution standards. ${ }^{50}$ While coastal states enjoy enforcement powers on a range of maritime security threats, their effective exercise might challenge navigational rights and freedom of navigation. These

45 D Guilfoyle, 'Maritime Law Enforcement Operations and Intelligence in an Age of Maritime Security' (2017) 93 Int'l Law Studies 299.

46 Case concerning the detention of three Ukrainian naval vessels (n 39) [64].

47 Ibid, [66].

48 J Kraska, 'Did ITLOS Just Kill the Military Activities Exemption in Article 298?' (2019) EJIL available at https://www.ejiltalk.org/did-itlos-just-kill-the-military -activities-exemption-in-Article-298/.

49 LOSC, Article 27. See also Klein (n 38) 586.

50 LOSC, Articles 73 and 220. 
hold an important place in LOSC as they have always been a prerequisite for military influence and international trade. ${ }^{51}$ Navigational rights are guaranteed in territorial seas and archipelagic waters where states can exercise their right of innocent passage and in international straits where they have the right of transit. ${ }^{52}$ Coastal states have an explicit right to 'prevent passage which is not innocent' or to even 'suspend temporarily in specified areas of its territorial sea the innocent passage of foreign ships if such suspension is essential for the protection of its security, including weapons exercises', but this right is confined to activities prejudicial to security as outlined in Article 19 LOSC. $^{53}$ On the other hand, states bordering straits shall not hamper or suspend transit passage, which emphasizes the importance of freedom of navigation in straits and limits enforcement powers for maritime security purposes. ${ }^{54}$ The freedom of navigation further limits the enforcement powers of coastal states in their EEZs where all states enjoy the freedom of navigation. ${ }^{55}$ LOSC has clearly outlined the enforcement powers of coastal states in the EEZ, which are mainly associated with fishing activities of foreign flagged vessels and the damage vessels can cause to natural resources and the marine environment, and is considered to have struck a fair balance between enforcement and navigational rights. ${ }^{56}$ However, with regard to maritime security threats not addressed by LOSC, such as the proliferation of WMDs or illegal bunkering, it is up to coastal states to show restraint and comply with the international law of the sea in the fight against maritime crime. This has proven difficult in practice, especially in cases where an illegal activity might threaten various security interests of the coastal state. Bunkering activities are such an example. '[B] unkering of foreign vessels engaged in fishing in the exclusive economic zone is an activity which may be regulated by the coastal State concerned', but coastal states do not have such competence with regard to other bunkering activities, such as bunkering of yachts sailing in the EEZ. ${ }^{57}$ The latter has been found to fall outside the jurisdiction of coastal states and within the freedoms flag states enjoy on the high seas. ${ }^{58}$ As a result, taking enforcement

51 Y Tanaka, 'Navigational Rights and Freedoms' in Rothwell, Oude Elferink, Scott and Stephens (n 38) 536-537.

52 LOSC, Articles 19, 52, 38.

53 See also LOSC, Articles 25 and 52.

54 LOSC, Articles 25 and 52.

55 LOSC, Article 58.

56 MA Becker, 'The Shifting Public Order of the Oceans: Freedom of Navigation and the Interdiction of Ships at Sea' (2005) 46 Harvard JIL 198; Klein (n 8) 97.

${ }_{57} M / V$ 'Virginia $G$ ' (Panama/Guinea-Bissau), Judgment, ITLOS Reports 2014, 4, [223].

${ }_{58}$ The $M / V$ 'Norstar' Case (Panama v Italy), Case No. 25, ITLOS, Judgment of 10 April 2019 [186]-[189]. 
measures against a vessel engaged in bunkering activities in the EEZ might be tantamount to violating freedom of navigation, even if these activities threaten maritime security. ${ }^{59}$ On the high seas, coastal states do not have enforcement powers but have the right of hot pursuit, which recognizes the right of coastal states to protect their interests against ships which have violated their laws and regulations. ${ }^{60}$ Although it is not clarified which laws and regulations must be violated in order for the right of hot pursuit to be engaged, it is accepted that serious maritime crimes, such as illegal fishing, terrorist attacks and damage to the marine environment, trigger Article 111. The right of hot pursuit, however, comes with serious restrictions and the main reason is that it might encroach upon the exclusive jurisdiction of the flag state, especially if the ship suspected of violations has reached the high seas.

This is because no state can claim sovereignty on the high seas and thus the role of enforcement is undertaken by flag states. Flag states have significant rights and duties under LOSC. Article 91 LOSC provides that a state can fix the conditions for the grant of its nationality to ships, which can then navigate freely on the high seas. ${ }^{61}$ As a counterpart, Article 94(1) imposes on flag states the duty to effectively exercise their jurisdiction and control in administrative, technical and social matters over ships flying their flag and Article 94(3) LOSC outlines the duties of flag states in terms of the construction, equipment and seaworthiness of ships, the manning of ships, labour conditions, the training of crews, the use of signals, the maintenance of communications and the prevention of collisions. Flag states have further enforcement powers under Article 217 LOSC, which details the measures they can take for the prevention, reduction and control of pollution of the marine environment from vessels that fly their flags. The according of nationality to vessels and the exercise of effective jurisdiction on board vessels by flag states are important tools against maritime crime. ${ }^{62}$ However, certain flag states set loose nationality conditions which result in dubious inspections or lack thereof for the sake of financial benefits to shipping companies that opt for lesser standards. The use of FoCs has been linked with the increasing numbers of illegal activities at sea, such as illegal fishing, marine pollution, the abuse of seafarers and proliferation of WMDs. ${ }^{63}$ Flag states with ineffective maritime administrations have been

\footnotetext{
LOSC, Articles 58 and 87.

LOSC, Article 111.

See also LOSC, Article 90.

62 RR Churchill and AV Lowe, The Law of the Sea (3rd edn, Manchester University

63 The Senate, Rural and Regional Affairs and Transport References Committee, Increasing use of so-called Flag of Convenience shipping in Australia (19 July 2017) available at https://www.aph.gov.au/Parliamentary_Business/Committees/
} Press 1999) 179. 
urged to enhance their legal procedures and enforcement capabilities and to suspend the registration of new vessels until such action is taken. ${ }^{64}$ However, these calls have often fallen on deaf ears and as a result states have decided to extend their law enforcement operations on the high seas in order to combat transnational maritime crime.

One way of doing this was by introducing a number of international treaties and other initiatives aimed at maximizing the use of the right of visit. Article 110 LOSC gives states the power to take certain steps - to request that a vessel show its flag, search a vessel and arrest those on board - against foreign flagged vessels on the high seas suspected of piracy, slave trade, unauthorized broadcasting, being without nationality or not displaying their true flag. The provision refers to specific crimes but accepts that other acts of interference might be derived from powers conferred by other treaties. ${ }^{65}$ In the case of piracy, for example, the direct reference in Article 110 LOSC provides a legal basis for counter-piracy operations. Nevertheless, the increase in acts of armed robbery in territorial waters and straits has compelled states to look beyond LOSC for other legal measures, such as the UN Security Council Resolutions or bilateral agreements, to suppress piracy. ${ }^{66}$ Undoubtedly, counter-piracy operations can be a deterrent to piracy, but the interdiction of vessels in territorial waters or straits can be a major obstacle to the freedom of navigation. Since littoral states enjoy sovereign rights in their territorial waters under LOSC, their consent to these operations might mitigate the problem. It is questionable though whether the interdiction of vessels suspected of armed robbery can be sanctioned in straits where the freedom of navigation attains higher significance and, as a result, the enforcement powers of states bordering straits narrow down to issues relating to safety of navigation, pollution control, illegal fishing, customs, fiscal, immigration or sanitary laws and regulations of states bordering straits. ${ }^{67}$

The slave trade is also explicitly mentioned in Article 110 LOSC but the modern threat of human trafficking by sea has prompted states to adopt the 2000 Protocol against the Smuggling of Migrants by Land, Sea and Air, Supplementing the Convention against Transnational Organized Crime (2000

Senate/Rural_and_Regional_Affairs_and_Transport/FOCShipping45/Report; AJ Marcopoulos, 'Flags of Terror: An Argument for Rethinking Maritime Security Policy Regarding Flags of Convenience' (2007-2008) 32 Tul. Mar. LJ 277.

${ }_{64}$ Report of the Secretary-General, Oceans and the law of the sea (10 March 2008) (A/63/63) [122].

65 LOSC, Article 110(1).

66 D Guilfoyle, 'Piracy Off Somalia: UN Security Council Resolution 1816 and IMO Regional Counter-Piracy Efforts' (2008) 57 ICLQ 698.

67 LOSC, Articles 42, 45(2) and 233. 
Migrant Protocol). ${ }^{68}$ Article 8 of the 2000 Migrant Protocol provides that a state party that has reasonable grounds to suspect a vessel exercising freedom of navigation of migrant smuggling can notify the flag state to request authorization for boarding and searching the vessel; and, if evidence of a smuggling offence is found, to take appropriate measures with respect to the vessel and persons and cargo on board. This provision again highlights the two key issues that law enforcement officials have to consider when fighting maritime crimes - the freedom of navigation and the exclusive flag state jurisdiction. While the provision empowers law enforcement agents to interfere with freedom of navigation in the event of a serious suspicion of an offence, the flag state is still to decide whether boarding or any other action against its vessel is needed.

The exclusive flag state jurisdiction poses further hurdles to the efforts of states to fight against illicit drug trafficking by sea. Through Article 17 of the 1988 Vienna Convention against Illicit Traffic in Narcotic Drugs and Psychotropic Substances (1988 Vienna Convention) ${ }^{69}$ states have sought to set up a procedure whereby a state may seek authorization - on an ad hoc basis or through prior arrangements between states - to board a vessel suspected of drug trafficking outside the territorial sea of any state. Article 17(3) of the 1988 Vienna Convention speaks explicitly of the rights of the flag state, which has to give prior authorization before maritime law enforcement officials can take any action against its ship..$^{70}$ The commentary on the 1988 Vienna Convention explains that

nothing in the Article was intended in any way to affect the rights of the flag State with regard to its vessel and there is no obligation on the flag State to provide the authorization requested; it is entirely within the discretion of that State to decide whether or not to allow another party to act against its vessel. ${ }^{71}$

68 Protocol against the Smuggling of Migrants by Land, Sea and Air, Supplementing the United Nations Convention against Transnational Organized Crime, 15 November 2000, 2241 UNTS 507. See also an evolutionary interpretation of slavery in response to the increase in migration: E Papastavridis, The Interception of Vessels on the High Seas: Contemporary Challenges to the Legal Order of the Oceans (Hart 2013) 269-270.

69 UN Economic and Social Council (ECOSOC), United Nations Convention against Illicit Traffic in Narcotic Drugs and Psychotropic Substances, 19 December 1988, 1582 UNTS 95.

70 W Gilmore, 'Drug Trafficking at Sea: The Case of R. v. Charrington and Others' (2000) 49 ICLQ 477.

71 Commentary on the 1988 Vienna Convention against Illicit Traffic in Narcotic Drugs and Psychotropic Substances done at Vienna on 20 December 1988, 328-329. 
This requirement limits the effectiveness of the provision, and states have attempted to overcome it through other bilateral and multilateral agreements. ${ }^{72}$ Bilateral agreements are considered more effective as it is easier for two states to agree between them a specific consent procedure. ${ }^{73}$ The US, for example, has put in place 'ship-rider' arrangements whereby an official would be placed on board a US coastguard vessel and would authorize interdictions of any vessels flying the flag of his/her state. Despite the effectiveness of these arrangements, they give rise to concerns over the influence the US can exert over smaller countries in the Caribbean. To avoid this risk, the 2003 Caribbean Agreement brought together some of the features of the various bilateral agreements between the US and Caribbean states in a more comprehensive manner. One way or another, what becomes evident is that exclusive flag state jurisdiction is challenged by the manner in which states respond to evolving maritime security threats.

In the context of illegal fishing, states also seem to take one step forward and two steps back when it comes to interfering with the exclusive flag state jurisdiction. This approach is reflected in the 1995 UN Agreement for the Implementation of the Provisions of the UN Convention on the Law of the Sea of 10 December 1982 relating to the Conservation and Management of Straddling Fish Stocks and Highly Migratory Fish Stocks (1995 Fish Stocks Agreement), which sets out principles for the conservation and management of those fish stocks. ${ }^{74}$ Under Article 18 of the 1995 Fish Stocks Agreement, flag states remain responsible for authorizing fishing on the high seas and enforcing the conservation and management measures. ${ }^{75}$ As a counterpart, third-state parties to the 1995 Fish Stocks Agreement can visit and inspect vessels suspected of illegal fishing. This seems to be a step towards limiting the powers of the flag state. However, the inspecting officials are required to give notice to the flag state and if they have serious grounds for believing that a serious offence has been committed, they must notify the flag state before any further

72 Agreement on Illicit Traffic by Sea, Implementing Article 17 of the United Nations Convention against Illicit Traffic in Narcotic Drugs and Psychotropic Substances (1995) 2136 UNTS 81; Agreement Concerning Co-operation in Suppressing Illicit Maritime and Air Trafficking in Narcotic Drugs and Psychotropic Substances in the Caribbean Area (2003).

$73 \quad$ Klein (n 8) 136.

${ }^{74}$ Agreement for the Implementation of the Provisions of the United Nations Convention on the Law of the Sea of 10 December 1982 relating to the Conservation and Management of Straddling Fish Stocks and Highly Migratory Fish Stocks, 4 August 1995, 2167 UNTS 3.

75 D Guilfoyle, Shipping Interdiction and the Law of the Sea (Cambridge University Press (CUP) 2009) 103-104. 
action is taken other than the collection of evidence. ${ }^{76}$ Article 21(7) and (12) of the 1995 Fish Stocks Agreement confirms that the enforcement powers of the flag state take precedence over those of the inspecting state, rendering the provisions ineffective where flag states do not comply with the conservation and management measures.

Maritime terrorism and proliferation of WMDs are not addressed in LOSC. States have therefore come up with new mechanisms to address these threats. Their non-inclusion in LOSC, however, does not mean that they are immune to the LOSC principles. This is evidenced by the Protocol of 2005 to the Convention for the Suppression of Unlawful Acts against the Safety of Maritime Navigation (2005 SUA Protocol), ${ }^{77}$ which, although it established a boarding procedure for vessels suspected of terrorism-related offences, still pays heed 'to the pre-eminence of the flag state in its authority over vessels on the high seas' ${ }^{78}$ The consent required for ship boarding has ultimately meant that its effectiveness largely depends on the willingness of flag states to suppress terrorism-related activities on board their vessels. To counter this weakness, it has been suggested that a new treaty is necessary for terrorism-related activities in territorial seas, straits, and archipelagic waters, signalling a further departure from the LOSC framework in search of effective means to achieve maritime security. ${ }^{79}$ To an extent, the US has sought support to do so through the Proliferation Security Initiative (PSI). ${ }^{80}$ The PSI is a political agreement rather than a binding treaty that aims to prevent the proliferation of WMDs and is intended to target state and non-state actors. In doing so, the participant states commit to boarding and searching their own vessels and vessels flying the flag of another participant state if there are serious suspicions of them carrying WMDs. On the high seas, the PSI states cannot board or search a foreign flagged vessel of a non-participant state without consent. While this restriction limits the effectiveness of the PSI, it was no doubt a necessary caveat to make PSI compatible with the international law of the sea. Despite the existing concerns, it is hard to accept that the PSI breaches established LOSC principles. In contrast, the increasing number of states joining PSI points towards an

76 Ibid, 105-108.

77 International Maritime Organization (IMO), Protocol of 2005 to the Convention for the Suppression of Unlawful Acts against the Safety of Maritime Navigation, 14 October 2005, LEG/CONF.15/21.

78 Klein (n 8) 178.

79 RC Beckman, 'Terrorism, Maritime Security and Law of the Sea: Challenges and Prospects' (2003) Singapore Maritime and Port J 114.

${ }_{80}$ RC Beckman, 'International Responses to Combat Maritime Terrorism' in VV Ramraj, M Hor and K Roach (eds), Global Anti-Terrorism Law and Policy (CUP 2005) 255-260. 
emerging acknowledgement of the need to reconsider the exclusive flag state jurisdiction and freedom of navigation in the name of maritime security. ${ }^{81}$

\subsection{Maritime Domain Awareness and Information Sharing}

Collecting and disseminating information about the oceans and the users of the oceans and their activities has emerged as a critical element to protecting maritime security. All the maritime security strategies refer to the importance of collecting information and putting in place the right information centres, agents or other mechanisms to enhance the processing and dissemination of this information among states and the shipping industry. It is questionable though whether such activities and the roles undertaken by state and non-state actors easily fit within LOSC.

First and foremost, it is important to understand what MDA means. The MDA policy was discussed in the US Maritime Security Strategy and, a month later, was detailed in the US National Plan to Achieve Maritime Domain Awareness. ${ }^{82}$ This defined MDA as 'the effective understanding of anything associated with the maritime domain that could impact the security, safety, economy, or environment of the United States'. ${ }^{83}$ It was noted that MDA is required to support maritime security as it gives states 'the ability to know, so that preemptive or interdiction actions may be taken as early as possible' ${ }^{84} \mathrm{It}$ is important to note that the MDA policy concerns the collection and sharing of information regarding non-nation threats, such as maritime terrorism, proliferation of WMDs, piracy, and environmental and other transnational crimes. ${ }^{85}$

This is essentially what distinguishes MDA from the other forms of intelligence-gathering activities directly addressed by LOSC. LOSC deals with marine scientific research, survey activities and hydrographic surveys, although none of them is clearly defined. These surveys are allowed under LOSC except where vessels exercise their right of innocent passage or transit. In these cases, the conduct of surveys could prejudice the security of the coastal state (Article 19) and would not be incidental to the normal mode of

${ }^{81}$ Proliferation Security Initiative, Endorsing States List (2 April 2019) available at https://www.psi-online.info/psi-info-en/botschaft/-/2205942.

82 US National Plan to Achieve Maritime Domain Awareness for the National Strategy for Maritime Security (October 2005) ii available at https://www.dhs.gov/ sites/default/files/publications/HSPD_MDAPlan_0.pdf.

${ }_{83}$ Ibid, ii. This definition has been endorsed by the IMO in MSC.1/Circ. 1415, Amendments to the International Aeronautical and Maritime Search and Rescue (IAMSAR) Manual 11 (May 25, 2012) http://www.mardep.gov.hk/en/msnote/pdf/ msin1242anx1.pdf.

84 Ibid, 1.

85 Ibid, 5. 
continuous and expeditious transit (Article 39). Assimilating MDA to marine scientific research and hydrographic surveys could legitimize them under LOSC. However, it is difficult to argue that the elements or goals of the MDA policy could match either those of marine scientific research, which is conducted 'for the purposes of scientific research', ${ }^{86}$ or of hydrographic surveys, which are intended to ensure the safety of navigation. ${ }^{87}$

MDA could potentially overlap with military surveys but their purposes also seem to be distinct. Military surveys are not directly addressed by LOSC but have been closely scrutinized in order to evaluate whether they can be accommodated or outlawed by LOSC. Military surveys 'refer to activities undertaken in the ocean and coastal waters involving marine data collection (whether or not classified) for military purposes, and can include oceanographic, marine geological, geophysical, chemical, biological and acoustic data ${ }^{98}$ The military purposes are nothing else but the defence of national security and the gain of military advantage. This immediately makes their conduct illegal within the territorial waters of a coastal state, but nothing in LOSC seems to ban them in the EEZ. In contrast, it has been argued that the reference in Article 58 LOSC to 'other internationally lawful uses of the sea' that states enjoy on the high seas under Article 87 could include military surveys. ${ }^{89}$ If one classifies the MDA policy as a military survey, this means that it will be allowed only on the high seas and possibly in the EEZ, without excluding the potential for causing inter-state disputes. Limiting the collection and dissemination of information on illegal activities by non-state actors at sea significantly limits the potential of states to tackle maritime security threats. This means that MDA should be distinguished from military surveys, although this results in the MDA policy falling beyond LOSC.

This might have further unwanted repercussions, as the development of the MDA policy might clash with some of the features of LOSC. One example is the development of maritime security zones for the purposes of monitoring illegal activities at sea. In 2014, Australia declared the establishment of the Australian 'Maritime Identification Zone' (MIZ), which extends 1,000 nautical miles from Australia's coastline. The purpose of this zone was to enhance maritime security by enabling the Australian naval forces to collect

86 Whaling in the Antarctic (Australia $v$ Japan; New Zealand intervening), ICJ, Judgment, General List No 148 (31 March 2014) [87]-[97].

87 S Bateman, 'Hydrographic Surveying in the EEZ: Differences and Overlaps with Marine Scientific Research' (2005) 59 Marine Pol'y 167-168.

88 JA Roach and RW Smith, 'Excessive Maritime Claims' (1994) 66 Int'l Law Studies 248

89 M Hayashi, 'Military and Intelligence Gathering Activities in the EEZ: Definition of Key Terms’ (2005) 59 Marine Pol'y 123-126, 130. 
information about vessels and their crews, passengers and cargoes seeking to enter Australian ports. Although one could accept the valuable contribution of the MIZ to pre-empting maritime security threats, its declaration challenges the zonal approach of LOSC and interferes with the maritime zones of neighbouring states..$^{90}$ It is also in stark contrast to the freedom of navigation states enjoy on the high seas. ${ }^{91}$

Even if MDA policies do not conflict with LOSC provisions, addressing them under LOSC will inevitably give rise to legal loopholes. The development of a successful global maritime network able to gather and exchange information demands effective cooperation among public, private and commercial stakeholders. LOSC, however, is aimed at regulating the activities of states rather than of non-state actors. This means that the activities of private and commercial institutions will have to be regulated not only in order to ensure that the MDA initiatives are effective, but also because it is vital that their intelligence gathering and dissemination activities do not violate the international law of the sea. One such example is the effort of the International Maritime Organization (IMO) to regulate the use of the vessel monitoring systems (VMS). VMS were first used by some shipping companies that sought to monitor the activities of their vessels in order to avoid marine accidents and vessel-sourced pollution. Their use, however, has expanded to include the monitoring of illegal fishing and surveillance of other maritime activities. To avoid their misuse and potential interference with sensitive government and commercial information, the IMO introduced the Automatic Identification System (AIS) and Long-Range Identification and Tracking (LRIT) system under SOLAS. ${ }^{92}$ Both systems are aimed at monitoring vessel traffic through collecting information about vessels, their position and crews, etc. for the purposes of security. Despite their shortcomings, they both reflect the importance of enhancing MDA in a clearly regulated manner, the achievement of which requires us to look beyond LOSC.

\section{THE EVER-CHANGING LANDSCAPE OF MARITIME SECURITY}

The analysis of law enforcement operations and MDA policies can only give a taste of the blend of threats and activities that synthesize the existing maritime security debate and challenge the LOSC framework. The contributors

90 N Klein, 'Legal Implications of Australia's Maritime Identification System' (2005) 55 ICLQ 361-362.

${ }_{91}$ Ibid, 342-352.

92 Guilfoyle (n 45) 306-309. 
to this collection will engage with several other threats and state responses to maritime security, some of which are not addressed or are only partially addressed by LOSC. Their discussions will reinforce the argument of this collection that LOSC - as a 'living instrument' - can accommodate some of the emerging maritime security threats and policies while others will inevitably fall beyond the LOSC framework, signalling a need for new responses. They will further show that, in spite of the innovative approaches and measures adopted by states, LOSC still circumscribes how far they can go in the name of maritime security.

Bueger and Edmunds will discuss, among other things, the development of the new maritime security agenda, while emphasizing that maritime security studies need to pay greater attention to the interconnectivity of different threats and issues, to novel forms of governance and order at sea, and to the dissemination of the new maritime security agenda through capacity building. Their contribution will also highlight that the emerging maritime security agenda not only challenges the international law of the sea, but also wider discussions in international relations and security studies.

Illegal fishing and disputes over marine resources hold an important place in the maritime security debate and will also be discussed in this volume. Barnes and Rosello will deal with the security threats posed by illegal fishing. Their evaluation of the LOSC framework will show that the latter indirectly acknowledges the impact of the regulation of fisheries on maritime security, but they will argue that fisheries governance is also interconnected with food security, human security and inter-state disputes. As a result, they will suggest that a new approach that combines some context sensitivity and awareness of cause and effect between fisheries and security is needed to address the destabilizing effect poor or ineffective regulation and management of fisheries have on maritime security. Roeben will discuss further challenges arising from high-end inter-state disputes concerning control of natural resources. He will argue that there is a new, although incomplete, trend to shift from a subjective to an objective grammar in the legal argumentation put forward by states in inter-state disputes, which could make it easier to resolve high-end disputes by enhancing inter-state cooperation.

One of the most topical issues in the maritime security debate concerns the 'robotic revolution' and its interplay with LOSC. The use of unmanned systems both by non-state actors and navies will therefore attract special attention in this collection. Petrig will evaluate the use of unmanned systems, which allows criminals to commit maritime offences from afar, challenging several LOSC provisions that require human involvement for the commitment of an offence. Petrig will conclude that it is difficult for LOSC to keep up with the 'robotics revolution'. This conclusion will be echoed by Chadwick, who will examine the use of unmanned systems by navies in response to maritime secu- 
rity threats. Chadwick will argue that it is difficult to fit all features and uses of unmanned systems under LOSC and greater clarity is needed as we currently run the risk of these new technologies operating in a grey zone. Chadwick's discussion on law enforcement operations and emerging maritime security threats will be complemented by Murdoch, who will deal with the risks posed to maritime security by ships without nationality. Murdoch will acknowledge that the LOSC framework does not expressly deal with the assertion of jurisdiction over ships without nationality, but he will argue that it provides a sufficiently accommodating framework for states to address maritime security threats posed by such ships.

The proliferation of state-led initiatives to tackle maritime security threats that LOSC cannot adequately address will be discussed in the last two contributions to this volume, reinforcing the idea that it is time that we accepted that LOSC cannot be a cure for all the evils in the maritime domain. Kopela will review the role that port states have been asked to play in securing the oceans. In her contribution, she explains how the ineffectiveness of flag states' enforcement of international standards on the high seas has led to the adoption of new IMO- and state-led initiatives intended to enhance ship and port security. Arguably, these initiatives have increased the powers of port states deviating from LOSC, but their effectiveness still depends on flag state compliance. Zou will also discuss a range of state-led initiatives adopted by countries in Southeast Asia to address both traditional and non-traditional maritime security threats, such as inter-state disputes, the safety of navigation and piracy. He will also argue that some security issues in the South China Sea cannot be adequately addressed by LOSC, pressing for the adoption of new measures.

\section{CONCLUSION}

Maritime security is a rapidly evolving and dynamic area of the law of the sea, but it cannot develop independently. There is a strong interplay between maritime security and LOSC which is evidenced in two ways. First, several maritime security threats are addressed directly or indirectly by LOSC, which therefore dictates what states can and cannot do to tackle them. In cases where LOSC does not provide effective solutions to these threats, or in cases where it does not refer to certain threats at all, states have come up with their own solutions. The last few years have witnessed the development of an unprecedented number of hard and soft law initiatives aimed at enhancing maritime security. States have acknowledged that LOSC - the 'Constitution of the Oceans' - only provides a limited range of solutions to the emerging issues raised and that the emerging threats and activities at sea require more innovative responses. These responses, however, have to be in accordance with LOSC. It is at exactly this point that frictions arise between maritime security policies and LOSC. 
Certain crucial components of the traditional law of the sea, such as freedom of navigation, flag state jurisdiction and the zonal approach, limit the responses of states, which in turn try to find new ways to overcome these limitations. As a result, it is time to accept that maritime security is a blend of ever-changing threats and activities which represents a new paradigm that cannot easily fit within the resource-oriented LOSC structure. This means that it ought to be accepted that LOSC can help tackle maritime security threats only to a limited extent, and that new threats and activities inevitably require new conceptual and conventional structures, as already evidenced by state practice. 